\title{
Synthesis, Spectral Characterization And Pharmacological Significance of Fe(III) Complex With Schiff Base and Thiocyanate ION as Ligands \author{
T.Ramachandramoorthy ${ }^{6}$
} \\ R. Govindharaju1 ${ }^{* 1}$, P. Durairaj ${ }^{2}$, N.Muruganantham ${ }^{3}$, V. Mukil Meenakshi ${ }^{4}$, T. Maruthavanan ${ }^{5}$,
}

\author{
${ }^{1,3}$ Department of Chemistry, Thanthai Hans Roever College (Autonomous), Elambalur, Perambalur - 621 220, Tamil Nadu, \\ India \\ ${ }^{2}$ Department of Chemistry, Excel Engineering College, Pallakkapalayam, Komarapalayam, Namakkal- 637 303, Tamil Nadu, \\ India \\ ${ }^{4}$ Department of Chemistry Government Arts College, Ariyalur, Tamil Nadu, India \\ ${ }^{5}$ Department of Chemistry, Sona College of Technology, Salem-636 005, Tamil Nadu, India \\ ${ }^{6}$ Department of Chemistry, Bishop Heber College (Autonomous), Tiruchirappalli- 620 017, Tamil Nadu, India.
}

Corresponding Author: argovindh@gmail.com, Mobile: +91 9444561010, +91042651011

Available online at: www.isroset.org

Received: 02/Jun/2019, Accepted: 19/Jun/2019, Online: 30/Jun/2019

\begin{abstract}
A novel Fe(III) complex of Schiff's base derived from phenylacetylurea condensed with salicylaldehyde (SBPS) and thiocyanate $\left(\mathrm{SCN}^{-}\right)$ion was synthesized by using microwave irradiation. Microwave synthesis gives high yield of the complex within a short time. The molecular formula and the probable geometry of the complex have been deduced from elemental analysis, molar conductance, UV, FT-IR, and Far IR spectra. The molar conductance indicates that the Fe(III) complex is a non-electrolyte. FT-IR spectra show that Schiff's base and thiocyanate ion are coordinated to the metal ion in a monodentate manner. The electronic spectrum and the magnetic moment indicate the geometry of the complex is found to be distorted octahedral. The antimicrobial activities of ligands and their Fe(III) complex were studied against the few microorganisms by agar - well diffusion method. The complex shows moderate activity against the bacteria and enhanced activity against the fungi as compared to the SBPS ligand.
\end{abstract}

Keywords: Fe(III) complex, SBPS, thiocyanate ion, antimicrobial

\section{INTRODUCTION}

The class of compounds, so-called imines, are often referred to as Schiff bases, named after the German chemist Hugo Schiff. Schiff bases contain the azomethine group $(-\mathrm{RC}=\mathrm{N}-)$ and are typically formed by the condensation of a primary amine with an active carbonyl compound. They have drawn considerable research attention of scientists owing to the ease of synthesis and metal complexation [1,2]. The schiff bases are interesting and substantial ligands find extensive applications in the field of coordination chemistry. Schiff bases also called as privileged ligands act as chelating ligands for many metal ions [3,4]. In modern years, there has been enhanced interest in the synthesis and characterization of transition metal complexes containing Schiff bases as ligands due to their importance as catalysts in many reactions. Also Schiff base complexes derived from heterocyclic compounds have acquired more attention in the field of bioinorganic chemistry because of their biological activities [5-16].

However, the schiff base has several applications in biological, clinical and analytical fields [17] due to their enhanced biological and pharmaceutical activities and the Schiff base have attracted many workers [18]. Schiff base ligand complexes are very important in many catalytic reactions [19]. It is also used in the di-oxygen uptake and oxidative catalyst [20,21]. Microwave-assisted synthesis is eco-friendly. This technique is certainly going to be the technology of tomorrow. The advantages of microwave reactions over conventional techniques are fast, clean, economic, pollution free, shorter time high yield [22,23]. 
In the present paper, the Schiff base is derived from phenylacetylurea and salicylaldehyde by condensation which is used in primary ligand for the preparation of Fe(III) complexes. The prepared complexes were characterized by the physico-chemical and spectral studies.

\subsection{MATERIALS AND METHODS:}

\section{EXPERIMENTAL}

Phenylacetylurea, potassium thiocyanate and iron nitrate were purchased from Alfa Aaser Company and used as such. The organic solvents used, viz., DMSO, DMF, methanol, ethanol which were of AnalaR grade, and used as such without further purification.

\subsection{Preparation of Schiff's base}

The Schiff's base (primary ligand) was prepared by refluxing an ethanolic solution of required mole ratios of phenylacetylurea with salicylaldehyde in the presence of $\mathrm{NaOH}$, for about an hour.
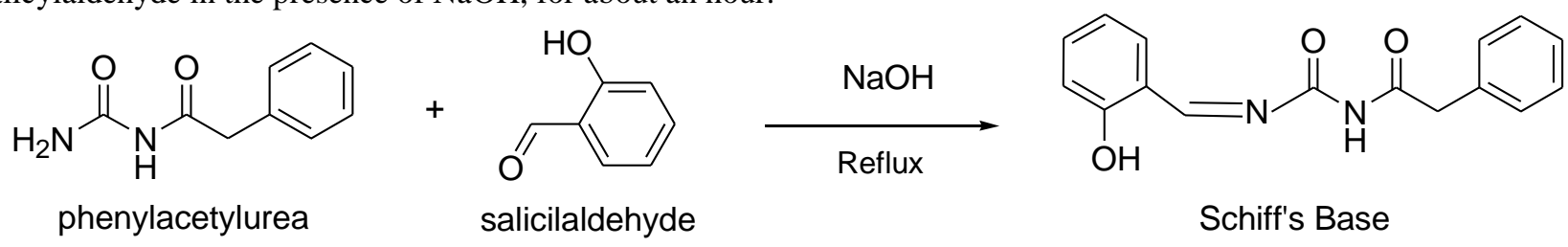

Fig. 1 Schiff's Base of Phenylacetylurea with Salicylaldehyde (SBPS)

\subsection{INSTRUMENTATIONS}

CHN elemental analyses were performed using Thermo Finnegan make, Flash EA1112 Series CHNS(O) analyzer. The electrical conductivity measurements were conducted using $10^{-3} \mathrm{M}$ solutions of the metal complex in acetonitrile with Systronic Conductivity Bridge (model number-304) at $30^{\circ} \mathrm{C}$. The UV-Visible spectrum of the Fe(III) complex was recorded on Varian, Cary 5000 model UV Spectrophotometer. Infra red spectra for the complex and the ligands were recorded on a Perkin Elmer, Spectrum RX-I, FT IR spectrometer in KBr discs at room temperature. The Far-IR Spectrum of the complex was recorded by Bruker 3000, FT IR Spectrometer. The antibacterial and antifungal activities of the ligand SBPS and the Fe(III) complex were determined by agar- well diffusion method.

\subsection{SYNTHESIS OF METAL COMPLEX}

$2.41 \mathrm{~g}(8.77 \mathrm{mmol})$ of SBPS in ethanol and $0.93 \mathrm{~g}(7.36 \mathrm{mmol})$ of potassium thiocyanate in ethanol were added to the iron nitrate $1.00 \mathrm{~g}(2.92 \mathrm{mmol})$ in methanol followed by microwave irradiation for a few seconds after each addition by using IFB $25 \mathrm{BG}-$ 1S model microwave oven. The resulting precipitate was filtered off, washed with 1:1 ethanol: water mixture and dried under vacuum. A pale brown colored complex was obtained with the yield of $76.1 \%$.

\section{PHARMACOLOGY}

\subsection{Antimicrobial activity:}

The Fe(III) complex and the ligands were tested for in vitro antimicrobial activity by the well diffusion method [24] using agar nutrient as the medium. The antibacterial and the antifungal activities of the ligands and the Fe(III) complex were evaluated by well diffusion method against the strains, cultured on potato dextrose agar as medium. The stock solution (10 $\left.{ }^{-2} \mathrm{M}\right)$ was prepared by dissolving the compounds in DMSO and the solutions were serially diluted to find Minimum Inhibitory Concentration values. According to the typical procedure [25] a well was made on the agar medium inoculated with the microorganisms. The well was filled with the test solution using a micropipette and the plate was incubated for 24 hours for bacteria and 72 hours for fungi at $35^{\circ} \mathrm{C}$. At the end of the period, inhibition zones formed on the medium were evaluated in millimeters (mm) and diameter.

\section{IV. . RESULTS AND DISCUSSION}

\subsection{Elemental analysis and metal estimation}

The elemental analysis and metal estimation of the complex lead to the formula $\left[\mathrm{M}(\mathrm{SBPS})_{3}(\mathrm{SCN})_{3}\right]$. The percentages of carbon, hydrogen, nitrogen and iron in the complex were found to be 56.87(56.83), 3.93(3.90), 11.70(11.73) and 5.18(5.13) respectively. The experimental data are in good agreement with the theoretical values (given in the parentheses). 


\subsection{Molar conductance}

The molar conductance of $10^{-3} \mathrm{M}$ solution of $\left[\mathrm{Fe}(\mathrm{SBPS})_{3}(\mathrm{SCN})_{3}\right]$ in acetonitrile was found to be $77.56 \quad \Lambda_{\mathrm{m}}\left(\Omega^{-1} \mathrm{~cm}^{2} \mathrm{~mol}^{-1}\right)$ indicating its non electrolyte [26] nature.

\subsection{Electronic Spectra:}

The electronic spectrum of Fe(III) complex gave three wavelength maximum at $680 \mathrm{~nm}\left(14,705 \mathrm{~cm}^{-1}\right), 385 \mathrm{~nm}\left(25,974 \mathrm{~cm}^{-1}\right)$, $260 \mathrm{~nm}\left(38,461 \mathrm{~cm}^{-1}\right)$ which corresponding transitions are ${ }^{5} \mathrm{E}_{\mathrm{g}} \rightarrow{ }^{5} \mathrm{~T}_{2} \mathrm{~g},{ }^{5} \mathrm{~B}_{1 \mathrm{~g}} \rightarrow{ }^{5} \mathrm{~B}_{2 \mathrm{~g}}$ and CT-band respectively [27]. The magnetic moment of $\mathrm{Fe}(\mathrm{III})$ complex is 5.8BM. These facts confirmed the six coordinated distorted octahedral geometry of the complex.

\subsection{FT-IR spectra}

The IR spectrum of the pure ligand shows the characteristic frequencies as follows: the band at $3388 \mathrm{~cm}^{-1}$ indicates the $v(\mathrm{~N}-\mathrm{H})$ stretching frequency of primary amine, at $1668 \mathrm{~cm}^{-1}$ indicates symmetric stretching frequency and at $1622 \mathrm{~cm}^{-1}$ the asymmetric stretching frequency of $v(\mathrm{~N}-\mathrm{H})$ in secondary amine. The $v(\mathrm{C}=\mathrm{O})$ stretching frequency of the ligand is observed at $1475 \mathrm{~cm}^{-1}$. In the Fe(III) complex, $v(\mathrm{~N}-\mathrm{H})$ is shifted to $1685 \mathrm{~cm}^{-1}$ and the symmetry stretching frequency at $\left(1619 \mathrm{~cm}^{-1}\right)$ is shifted to $1605 \mathrm{~cm}^{-1}$ which confirms the entry of ligands into the coordination sphere. In addition to that, the value at $2068 \mathrm{~cm}^{-1}$ indicates the presence of $\mathrm{SCN}^{-}$in the coordination sphere of the complex [28-31].

\subsection{Far-IR Spectra}

In the Far-IR spectrum of the complex, the frequency at $448.5 \mathrm{~cm}^{-1}$ corresponds to $\mathrm{HC}=\mathrm{N}$ bond and at $342.2 \mathrm{~cm}^{-1}$ indicates the $\mathrm{Fe}-\mathrm{N}$ (from thiocyanate) bond [32] thus, it is confirmed.

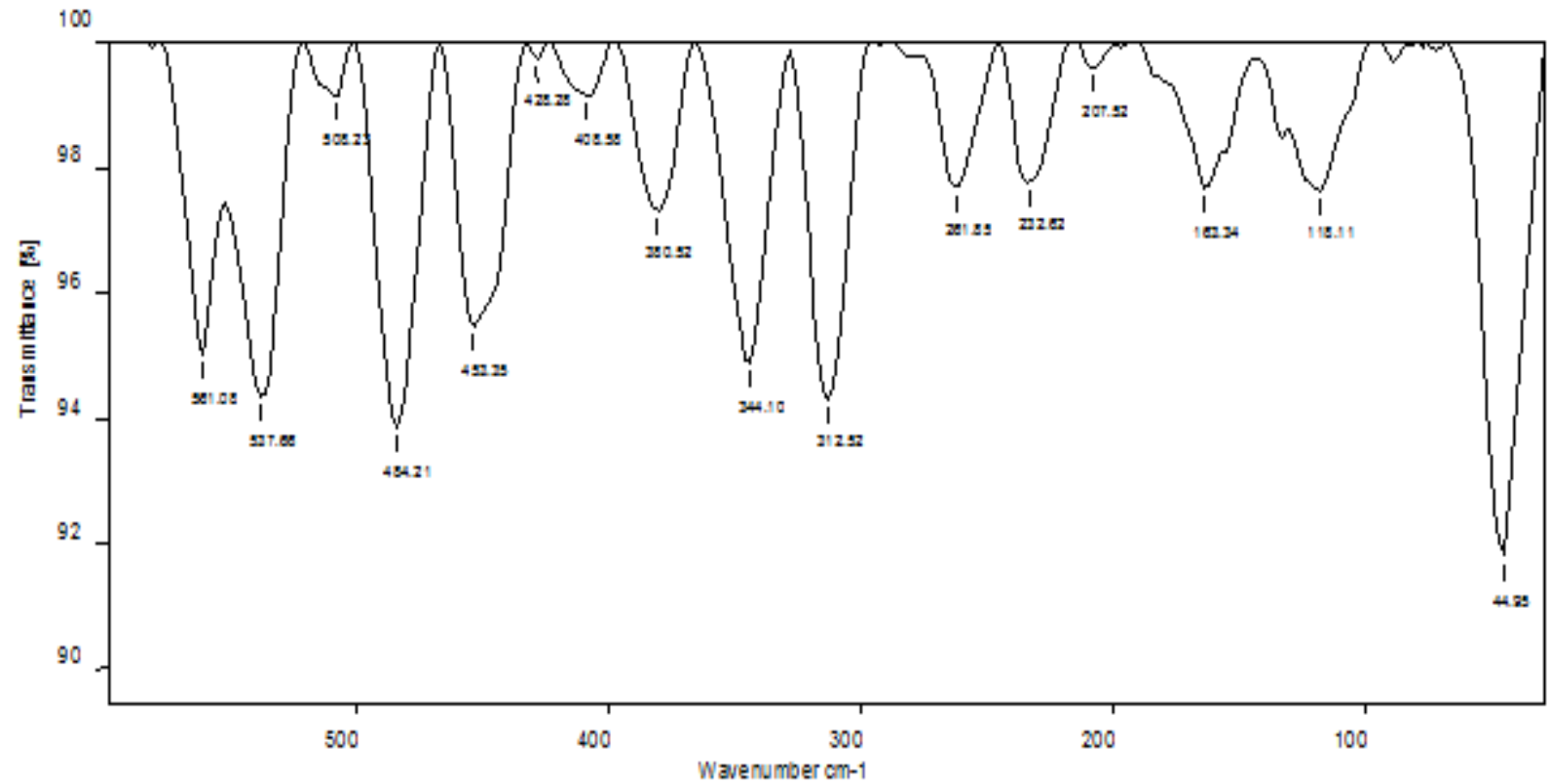

Fig. 2 Far-IR-spectrum of Fe(III) complex

\subsection{CYLCLIC VOLTAMMOGRAM OF Fe(III) COMPLEX:}

Cyclic voltammogram of Fe(III) complex was recorded in DMSO solution. This shows a well redox process corresponding to the formation of $\mathrm{Fe}(\mathrm{III}) / \mathrm{Fe}(\mathrm{II})$ couple at $\mathrm{Epa}=-0.900 \mathrm{~V}, \mathrm{Epc}=-0.480 \mathrm{~V}$ and the $\Delta \mathrm{Ep}=0.420 \mathrm{~V}$.This also indicates the quasireversible [33] nature of one electron transfer reactions. 


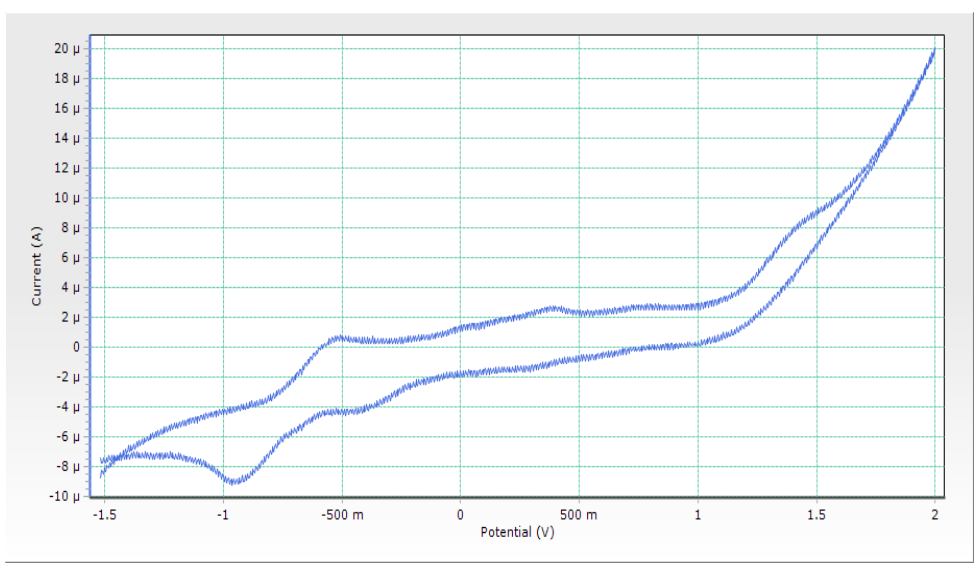

Fig.3 Cyclic voltammogram of Fe(III) complex

\section{BIOLOGICAL ACTIVITY}

\subsection{Antibacterial activity}

The synthesized Fe(III) complex and the free ligands were evaluated against the bacteria E.coli, Klebsiella Pneumonia, P.aeurginosa, S. aureus, Bacillus cereus. Aspergillusflavus, Aspergillusniger, Aspergillusoryzae, Aspergillussojae and Candida albicans at MIC concentration using agar-well diffusion method. The complex shows does not active against the tested microbes. The antibacterial activities of the free ligands and the complex are as shown in Table1.

Table 1. Antibacterial activity

\begin{tabular}{|r|c|c|c|c|c|c|}
\hline \multirow{2}{*}{ S.No } & \multirow{2}{*}{$\begin{array}{c}\text { Ligand } \\
\text { /Complex }\end{array}$} & \multicolumn{5}{|c|}{ Zone of Inhibition(mm) } \\
\cline { 3 - 7 } & S.aureus & Bacillus cereus & E.coli & P.aeruginosa & \multirow{2}{*}{ Klebsiella } \\
\hline 1 & $\mathrm{SBPS}$ & 6 & 10 & 10 & 6 & 5 \\
\hline 2 & {$\left[\mathrm{Fe}(\mathrm{SBPS})_{3}(\mathrm{SCN})_{3}\right]$} & 5 & 6 & 5 & 5 & 6 \\
\hline
\end{tabular}

\subsection{Antifungal activity}

The synthesized compounds and the free ligands were evaluated against the fungi, viz., Aspergillus flavus, Aspergillus niger, Aspergillus oryzae, Aspergillus sojae and Candida albicans at various concentration and compared to pure SBPS and KSCN. But, the antifungal activities of all the complexes are lower than those of Fluconazole (standard).The complex shows enhanced activity against the tested fungus. The antifungal activities of the free ligands and the complex are as shown in Table 2.

The complex shows high antifungal activity against Aspergillus sojae $(30 \mathrm{~mm})$, moderate activities against Aspergillus flavus $(23 \mathrm{~mm})$ and Aspergillus niger $(24 \mathrm{~mm})$, and low activity against Candida albicans $(21 \mathrm{~mm})$. The results are given in Table2.

Table 2. Antifungal activity

\begin{tabular}{|c|c|c|c|c|}
\hline \multirow{2}{*}{ S.No } & \multirow{2}{*}{ Fungus } & \multicolumn{3}{|c|}{ Concentration } \\
\hline & & $100 \mu \mathrm{gml}^{-1}$ & $200 \mathrm{mgml}^{-1}$ & $400{\mu \mathrm{gml}^{-1}}^{-1}$ \\
\hline 1 & Aspergillus flavus & 6 & 11 & 23 \\
\hline 2 & Aspergillus niger & 9 & 14 & 24 \\
\hline 3 & Aspergillus oryzae & 4 & 11 & 21 \\
\hline 4 & Aspergillus sojae & 13 & 21 & 30 \\
\hline 5 & Candida albicans & 5 & 12 & 21 \\
\hline
\end{tabular}

However, the antimicrobial activity values indicate that the complexes possess higher growth of inhibition potential compared to those of their free ligands. The antibacterial activity of the metal complexes increase with the increase in the concentration of the complexes. It suggests that the complexes having antibacterial activities inhibit multiplication process of the microbes by blocking their active sites [34]. The increased activity of the metal complexes can be explained on the basis of chelation theory [35]. It is known that chelation tends to make the ligand act as powerful and potent bactericidal agents, killing more number of 
bacteria than the ligand. It is observed that, in a complex, the positive charge of the metal is partially shared by the donor atoms present in the ligands, and there may be $\pi$-electron delocalization over the whole chelating space [36].

\section{CONCLUSION}

In the present study, our efforts were to synthesize and characterize a new Fe(III) metal complex with SBPS and thiocyanate ion as ligands. The new complex was synthesized using microwave irradiation (Green synthesis). These synthesized compounds were characterized by various chemical and spectral analyses. Based on the analytical, electrical conductance, spectral and magnetic moments data, distorted octahedral geometry has been suggested for the Fe(III) complex. The antibacterial and the antifungal activities of the ligands were compared with the Fe(III) complex. The complex shows does not active against the bacteria and enhanced activity against the fungus.

\section{ACKNOWLEDGEMENT}

The authors thank the Management and the Principals of Thanthai Hans Roever College (Autonomous), Perambalur, Tamil Nadu, India for permitting them to carry out this work. The authors are also thankful the Heads, SAIF, IIT Madras, IIT Roorkee, IIT Bombay and the Director, STIC, Cochin for providing the spectral data collection.

\section{REFERENCES}

[1]. A.W. Jeevadason, K.K. Murugavel and M.A. Neelakantan, Renew. Sustain. Energy Rev. 36, 220-227 (2014).

[2]. Zhang, Jie, Linli Xu and Wai-Yeung Wong, Coordination Chemistry Reviews, 355 180-198 (2018).

[3]. Saritha Aduri, Venkata Ramana Reddy, Sireesha, Der Pharma Chemica, 9(2) 90-98 (2017).

[4]. S. Sangeeta, K. Ahmad, N. Noorussabah, S. Bharti, M.K. Mishra, S.R. Sharma, M. Choudhary, Journal of Molecular Structure, 1149183 (2017).

[5]. Violeta Jevtovic, Research In Cancer and Tumor, 3(1) 1-5 (2014).

[6]. Md. Saddam Hossain, Pijush Kanti Roy, Roushown Ali, C. M. Zakaria, Md. Kudrat-E-Zahan, Clinical Medicine Research, 6(6) 177-191 (2017).

[7]. M.S.Hossain, M.A.Islam, C.M.Zakaria, M.M. Haque and M.A. Mannan, J Chem Bio Phy Sci, 6: 041-052 (2016).

[8]. Md. Saddam Hossain, C.M Zakaria, Md. Kudrat-E-Zahan and B.Zaman, Der Chemica Sinica, 8(3) 380-392 (2017).

[9]. M.S.Hossain, C.M. Zakaria, M.M Haque and M.Kudrat-E-Zahan, Int J Chem Stud 4: 08-11 (2016).

[10]. Farhana Afsan, Sadia Afrin Dalia, Saddam Hossain, Shaheen Sarker and Kudrat-E-Zahan, Asian Journal of Chemical Sciences, 4(3) 1- 19 (2018). Article no.AJOCS.40913.

[11]. N.K.Gondia, J.Priya and S.K.Sharma, Res Chem Intermed., 431165- 1178 (2017).

[12]. Sunita Bhanuka, Har Lal Singh, Rasayan J. Chem.,10(2) 673- 68, (2017).

[13]. K.P.Satheesh, V.Suryanarayana Rao, J. of Adv. Scien. Res., 6(2) 14-17 (2015).

[14]. Mohammad Asif., Int. J. of Cur. Res. in App. Chem. \& Chem. Eng., 3(1) 20-29 (2017).

[15]. P.K. Das, N.Panda and N.K. Behera, IJISET - Int. J. of Innovative Sci., Eng. \& Tech. 3(1) $42-54$ (2016).

[16]. Gupta, Meenakshi and Vijay Kumar Vaidya, Sciences (IRJPMS) 2.2 36-38 (2019).

[17]. A.P. Mishra and Monika Soni, Metal Based Drugs, 1-7, (2008).

[18]. R. K. Dubey, U.K. Dubey and C.M. Mishra, Indian Journal of Chemistry, 47A, 1208-1212 (2008).

[19]. K. Krishnankutty, MuhammedBasheerUmmathur and P. Sayudevi, AnalesdelaAsociaciaQuimica, Argentina, 96(1-2), 1-8, (2008).

[20]. S. Sarkar and K. Dey, Spectrochim Acta A Mol Biomol Spectrosc.,62(1-3), 383-93 (2005).

[21]. D. M. Boghaei and M. Lashani-Zadegan, J. Sci. Ir. Iran, 11(4), 301-304 (2000).

[22]. S. Ravichandran and E. Karthikeyan, International Journal of Chem Tech Research, 3(1), 466(2011).

[23]. Dusmanta Kumar Pradhan, T.S. Dharmarajan, ManasRanjan Mishra and Ashutosh Mishra, Int. J. Res. Dev. Pharm. Life. Sci., 1(2), 44 (2012).

[24]. O. N Irobi, M.Moo - Young and W.A.Anderson, Int . J. Pharm., 34, 87 (1996).

[25]. M.J. Pelczar, E.C.S. Chan and N.R.Krieg, Microbiology (New York: Blackwell Science) $5^{\text {th }}$ edn., 1998.

[26]. W. G. Geary, Coord. Chem. Rev., 7, 81-122 (1971).

[27]. Arun Kumar, Monika Agarwal and AjaiK.Singh, Polyhedron, 27(2), 485-492 (2008).

[28]. Liu, Xiang, Carolina Manzur, Nestor Novoa, Salvador Celedon, David Carrillo, and Jean-Rene Hamon, Coordination Chemistry Reviews, 357 , 144-172 (2018).

[29]. M. Gaber, N. El-Wakiel, N., El-Baradie, K., \& Hafez, S. Journal of the Iranian Chemical Society, 16(1), 169-182 (2019).

[30]. V.B. Kartha, and N.D Patel, J. Chem. Soc, Part-I, pp 952 (1967).

[31]. A.Arunachalam, T. Ramachandramoorthy, S. Padmavathy S. Amalafathima Rani, International Journal of Pharmacy and Pharmaceutical Sciences, 6(8), 91-94 (2014).

[32]. Zahid. H. Chohan., AsifaMunawar and Claudiu T. Supuran, Metal Based Drugs, 8(3), 137-143 (2001).

[33]. Devar M. Boghaei and SajjadMohebi, Journal of Molecular catalysis A: chemical, $179 \quad$ (1-2), 41-51 (2002).

[34]. J. W. Park and Y. H. Paik, Bull. Korean Chem. Soc., 6, 23 (1985).

[35]. S. K. Sengupta, O. P. Pandey, B. K. Srivastava and V. K. Sharma, Transit. Met. Chem., 23, 349-353 (1998).

[36]. R. Ahmad, A. M. Ali, D. A. Israf, N. H. Ismail, K. Shaari and N. H. Lajis, Life Sci., 76, 1953-1964 (2005). 


\section{Author's Profile}

Dr. R. Govindharaju is currently working as Assistant Professor, PG \& Research Department of Chemistry, Thanthai Hans Roever College (Autonomous), Perambalur, Tamil Nadu, India. He has awarded with a Ph.D. Degree in Chemistry from Bharathidasan University, Tamil Nadu, India in 2017. The authors have published more than 20 research papers in reputed international journals.

Dr. P.Durairaj is currently working as Assistant Professor, Department of Chemistry, Excel Engineering College, Pallakkapalayam, Komarapalayam, Namakkal, Tamil Nadu, India.. He has awarded with a Ph.D. Degree in Chemistry from Bharathidasan University, Tamil Nadu, India in 2018. The author has published more than 65 research papers in reputed international journals.

Dr. N. Muruganantham is currently working as Assistant Professor, PG \&Research Department of Chemistry, Thanthai Hans Roever College (Autonomous), Perambalur, Tamil Nadu, India. He has awarded with a Ph.D. Degree in Chemistry from Bharathidasan University, Tamil Nadu, India in 2018. The author has published more than 65 research papers in reputed international journals.

V. Mukil Meenakshi is a research scholar, PG \&Research Department of Chemistry, Government Arts College, Ariyalur, Tamil Nadu, India. She has completed M.Sc., Degree in Chemistry from Madurai Kamaraj University, Tamil Nadu, India.

T. Maruthavanan is currently working as Assistant Professor, Department of Chemistry, Sona College of Technology, Salem, Tamil Nadu, India. The author has published more than 50 research papers in reputed international journals.

T. Ramachandramoorthy (Rtd), Professor, PG \& Research Department of Chemistry, Bishop Heber College (Autonomous), Tiruchirappalli, Tamil Nadu, India. The author has published more than 150 research papers in reputed international journals. 